\title{
A feminist in the academy
}

Cite as: CMAJ 2017 November 13;189:E1398-9. doi: 10.1503/cmaj.170841

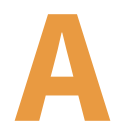

s I returned from maternity leave to my fellowship in infectious diseases, I was desperate to prove that I was still a "good doctor" and a "good mother." Yet, after a week of rounding, reading around cases, scrambling to pump breast milk in call rooms, racing home for bedtime and revising manuscripts at night, I was the one who needed antibiotics. I was having the first of several painful episodes of mastitis after my return to work. Only later did I find a network of colleagues who let me pump, discuss career options and vent my maternal guilt in the safe spaces of their offices.

Women make up more than half of most medical school classes across the country. ${ }^{1}$ Statistics, however, cannot tell us about the experience of navigating the academic medical space as a woman. Although we are beginning to discuss female representation in academia, we seldom question what a career in academic medicine can and should look like for men and women alike. As many clinicians will attest, when balancing clinical work, academic commitments, marriage, children and aging parents, something must give. So what gives, in the end? A study of medical marriages suggests that it is we, and not our institutions, who bend: we take up greater household and child care responsibility, we support each other through illness, gruelling residencies and time-consuming conference circuits, all while unflaggingly committing to our careers. ${ }^{2}$ It is little surprise that many women (and men) find these double shifts exhausting.

What if institutions were structured to allow people to meet their own personal and familial needs, as well as those of patients and the academy? What would be such an institution's metrics of success? What would working there feel like? What would a "feminist" academic institution look like?

Feminism has evolved, from the suffragefocused "first-wave feminism," to the legal-,

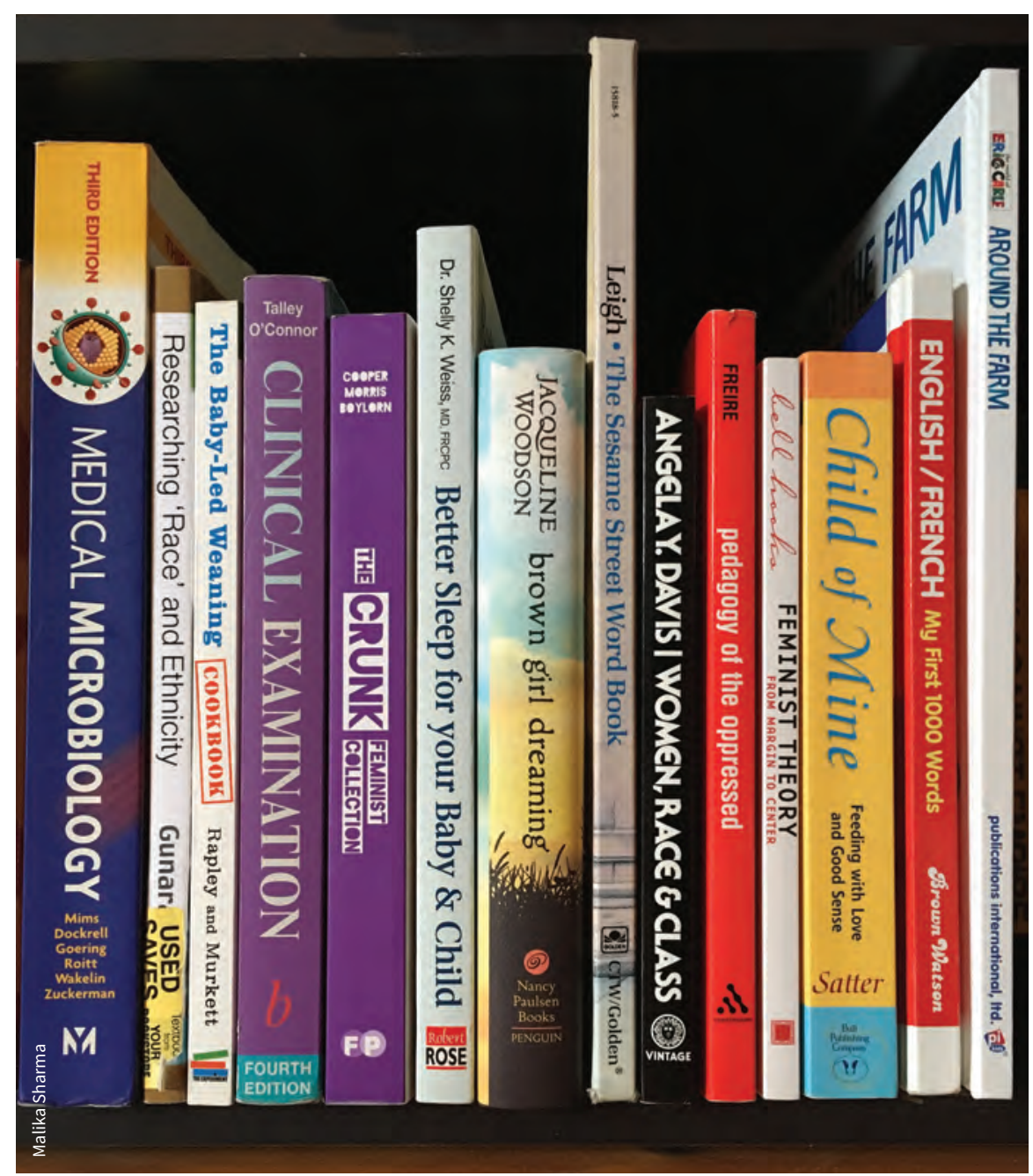

reproductive- and workplace-inequalityfocused "second-wave." Contemporary conversations about women in academic medicine have largely drawn from this "second wave," yet important critiques of this iteration include its failure to incorporate or account for the perspectives of racialized and queer women - critiques that have led to feminism's "third wave." Feminist academic institutions would need to go beyond demographic representation, which does not necessarily engender cultural shift - the pipeline to leadership positions remains leaky, with little discussion of how race, religion or sexual orientation, for example, affect who ultimately "makes it to the top."

Modern academic medical institutions are male dominated, despite the "feminization" of medicine. This male dominance, or patriarchy, "does not relate to a cultural context that refers only to men, but refers to a dominant cultural form based on a particular kind of logic that embraces heroism, rationalism, certainty, the intellect, distance, objectification, and explanation before appreciation." ${ }^{3}$ Trainees learn about 
"great diagnosticians" (all men) and "great scientists" (almost invariably men), with female practitioners and scholars "buried and diminished in male-centered scholarship." 4 Sometimes the "very content of education validates men even as it invalidates women." ${ }^{\prime 5}$ For example, medical students know Marion Sims through his eponymous speculum, but are unlikely to learn that his advances in vesicovaginal fistula repair were gained through experimentation on unanesthetized, enslaved black women. Research and standard-setting can similarly invalidate women's experiences and knowledge, as evidenced by the history of tampon standardization. ${ }^{6}$ Flexner's pivotal report systematically excluded women and African-Americans from medical training, as a result of his recommendations to close socalled underperforming schools. ${ }^{7}$ Medical education, through its silences, can erase history - a history replete with examples of participation in colonial practices, the transatlantic slave trade and misogyny. Further, it can perpetuate existing power dynamics between patient and provider, by invalidating experiences of racial or colonial trauma in the clinical encounter, or by divorcing public health education from the broader social, political and economic conditions of peoples' lives. ${ }^{8}$ Feminizing academic medicine would require a fundamental reimagining by educators, administrators and clinicians. For instance, the clinical encounter could be restructured to be family centred and trauma informed, and curricula could be reoriented with respect to social justice as a means of achieving individual and population health. Organizational missions, values and structures could be reappraised, with concomitant changes to how students and faculty are recruited and retained.

I have struggled to understand how I fit into this system - am I victim or perpetrator? Oppressor or oppressed? I have had to reconcile my own conflicting race-, genderand class-based privilege, particularly the powers granted to me by my socioeconomic status and cultural capital in the form of my medical degree. I cannot see myself as distinct from my profession - I am both critiquing from my place outside and complicit from my place within. Feminist scholar and poet Adrienne Rich warns "one of the dangers of a privileged education for women is that we may lose the eye of the outsider and come to believe that those [dominant cultural] patterns hold for humanity, for the universal, and that they include us." 4

I have not found inspiration in Sheryl Sandberg's call to "lean in." To do so, we often outsource what is traditionally considered "woman's work." Women (and men) are seldom encouraged to question why this is considered "women's work" and to whom are we outsourcing this labour - often to women of colour from low-income settings, who thus effectively allow the academic establishment to function and our own careers to flourish. While we are leaning in, are we acknowledging how much and who we are "leaning on"? Sandberg's feminism has the dangerous potential to erode solidarity among women across the spectrum of racial, economic and social experiences. ${ }^{9}$ Again, if physicians are called to act as advocates for our patients, how does a narrow worldview - one that fails to link the devaluing of "women's work" with broader socioeconomic forces and neglects to question unequal, patriarchal and racialized distributions of labour within our own contexts - diminish the revolutionary potential of women in medicine? Women in the academy have the potential to use their skills and knowledge to "work to transform the realm of health care ... to make them responsive to the needs of all those women, people of colour, children, the aged, the dispossessed."

I had worried that having a child would make me insular and inward gazing. Instead, it has given me a deeper sense of connection and solidarity with people pushed to the margins in our society. I have never been more aware of the critical issues of parental leave, affordable child care, equitable division of labour and austerity measures that result in low pay and poor working conditions for early childhood educators. I have a deeper sense of kinship with women protesting the killing of their black and brown children in Ferguson and Baltimore. Being a "mother in medicine" has allowed me to better understand how I can express and participate in "profound and ... radical politics [that] come directly out of [my] own identity, as opposed to working to end somebody else's oppression." ${ }^{10}$ In other words, rather than seeing myself as a saviour who advocates on behalf of my patients, I can position myself as an ally who can work with communities. Rather than "speaking for" or even "amplifying the voice of" marginalized people, I can instead pass the microphone. I do not think parenthood is the only portal to access these perspectives, but for me it has been a radically transformative experience.

I am privileged to be doing meaningful work. Yet, in many ways, I remain an outsider - for "no woman is really an insider in the institutions fathered by masculine consciousness." ${ }^{4}$ Reconciling the roles I play (physician, medical education researcher, wife, mother) is essential if I am to practice, teach and live with integrity, which is ultimately about achieving "congruence or agreement between what we think, say, and do." 11 Thinking through these issues, as in this essay, is one way in which I am trying to live, practice and research with integrity.

\section{Malika Sharma MEd MD}

Wilson Centre for Research in Education, University of Toronto; Maple Leaf Medical Clinic, Toronto, Ont.

This article has been peer reviewed.

\section{References}

1. Burton KR, Wong IK. A force to contend with: the gender gap closes in Canadian medical schools. CMAJ 2004;170:1385-6.

2. Perlman RL, Ross PT, Lypson ML. Understanding the medical marriage: physicians and their partners share strategies for success. Acad Med 2015;90:63-8.

3. Bleakley A. Gender matters in medical education. Med Educ 2013;47:59-70.

4. Rich A. What does a woman need to know. In: Blood, bread and poetry: selected prose, 1979-1985. New York: Norton; 1986:1-10.

5. Rich A. Taking women students seriously. The Radical Teacher 1979;11:40-3.

6. Vostral S. Toxic shock syndrome, tampons and laboratory standard-setting. CMAJ 2017;189:E726-8.

7. Steinecke A, Terrell C. Progress for whose future? The impact of the Flexner Report on medical education for racial and ethnic minority physicians in the United States. Acad Med 2010;85:236-45.

8. Sharma M, Pinto AD, Kumagai AK. Teaching the social determinants of health: A path to equity or a road to nowhere? Acad Med 2017 Apr. 25 [Epub ahead of print]. doi:10.1097/ ACM.0000000000001689.

9. Hooks B. Dig deep: beyond lean in. The Feminist Wire; 2013. Available: http://thefeministwire. com/2013/10/17973/ (accessed 2017 Sept. 17).

10. The Combahee River collective statement: A black feminist statement. In: Smith B, editor. Home Girls: A black feminist anthology. New Brunswick (NJ): Rutgers University Press; 1983:272-82.

11. Hooks B. Teaching critical thinking: practical wisdom. New York: Routledge; 2010. 